\title{
Influencial factors of the performance of interferon- $\gamma$ release assays in the diagnosis of childhood tuberculosis
}

\author{
Tao Li $\cdot$ Lei Bao $\cdot \mathrm{Ni}$ Diao $\cdot$ Feng Sun $\cdot$ Yan Gao $\cdot$ Ka-Wing Wong \\ Xiuhong Xi $\cdot$ Xuhui Liu $\cdot$ Sen Wang $\cdot$ Jing Wu - Ma Hui $\cdot$ Xiaoyong Fan \\ Ying Zhang $\cdot$ Wenhong Zhang $\cdot$ Shuihua Lu
}

Received: 3 March 2014/ Accepted: 7 May 2014/Published online: 13 June 2014

(C) The Author(s) 2014. This article is published with open access at Springerlink.com

\begin{abstract}
Diagnosis of active tuberculosis (TB) in children remains difficult. This study aimed at evaluating the ability of interferon-gamma release assays (IGRAs) in the detection of active TB in human immunodeficiency virusnegative children vaccinated with Bacille Calmette-Guérin and investigating the effect of prednisolone treatment on the IGRAs performance. Among the 162 children with suspected TB disease recruited in China, 60 were tested with QuantiFERON-TB Gold In Tube (QFT-GIT) and 102 were tested with T-SPOT.TB. QFT-GIT presented a sensitivity of $83.9 \%$ (95\% CI 66.9-93.4\%) and a specificity of $88.5 \%$ (95\% CI 70.2-96.8\%), while T-SPOT.TB had
\end{abstract}

Tao Li and Lei Bao have contributed equally to this study.

T. Li · K.-W. Wong $\cdot$ X. Xi · X. Liu - M. Hui · X. Fan

S. Lu ( $\triangle)$

Shanghai Public Health Clinical Center, Fudan University,

Shanghai, China

e-mail: tubercle@shaphc.org

T. Li $\cdot$ L. Bao - N. Diao · F. Sun $\cdot$ Y. Gao - S. Wang

J. Wu $\cdot$ W. Zhang $(\bowtie)$

Department of Infectious Diseases, Huashan Hospital, Fudan

University, Shanghai, China

e-mail: zhangwenhong@fudan.edu.cn

K.-W. Wong

School of Basic Medical Sciences, Shanghai Medical College, Fudan University, Shanghai, China

Y. Zhang

Department of Molecular Microbiology and Immunology, Bloomberg School of Public Health, Johns Hopkins University, Baltimore, MD, USA

W. Zhang

Institutes of Biomedical Sciences, Fudan University, Shanghai, China a sensitivity of $75.9 \%(95 \%$ CI $63.4-85.2 \%)$ and a specificity of $94.7 \%$ (95\% CI 81.8-99.5\%). The positive predictive value was high in both assays, $92.9 \%$ for QFTGIT and $95.7 \%$ for T-SPOT.TB. In total of these two kinds of IGRAs, false negative rate was significantly higher in children receiving systemic prednisolone $(1 \mathrm{mg} / \mathrm{kg} /$ day $)$ therapy for $>1$ week (two tested with T-SPOT.TB and five tested with QFT-GIT) than in those with $\leq 1$ week of prednisolone therapy and without prednisolone therapy (57.1 vs. $18.3 \%, p=0.035$ ). There was no significant difference of the positive rate of both tests in children $<5$ years old compared with those $\geq 5$ years old. Both types of IGRAs showed good diagnostic values in detecting childhood TB before microbiological evidence was available. Glucocorticoids had a significant negative influence on IGRAs if treated for $>1$ week. Age made no difference on the performance of these tests in children.

Keywords Interferon- $\gamma$ release assays $\cdot$ Childhood tuberculosis $\cdot$ Diagnosis $\cdot$ Prednisolone $\cdot$ Age

\section{Introduction}

Tuberculosis (TB), caused by Mycobacterium tuberculosis (MTB), has infected approximately one third of the global population. There were 8.7 million incident cases and 1.42 million deaths in 2011. Data on the global burden of childhood TB was not available until 2012, when the World Health Organization (WHO) first reported estimates of 490,000 new cases and 64,000 deaths in 2011 [1]. Although China ranks second among the high-burden countries for tuberculosis, with a total of 1.4 million TB patients with 1 million new cases per year, there is no epidemiological data of childhood TB in China. 
Diagnosis of childhood tuberculosis is especially difficult because of the atypical clinical and radiological presentations and lack of sputum production in young children. Tuberculin skin test (TST) has been the main screening test for MTB infection since last century. However, false-positive results could occur because diagnostic antigens used in TST have cross-reactions with nontuberculous mycobacteria or Bacille Calmette-Guérin (BCG) vaccine [2]. $\mathrm{T}$ cell-based IFN- $\gamma$ release assays (IGRAs) measure the release of IFN- $\gamma$ after in vitro stimulation with MTB-specific antigens, such as early secreted antigenic target 6 (ESAT-6) and culture filtrate protein 10 (CFP 10). Thus, the IGRAs have the ability to reduce falsepositive results and show higher sensitivity and specificity than TST [3-5]. There are two commercially available IGRAs tests: the whole blood-based QuantiFERON-TB Gold in Tube (QFT-GIT) and the PBMC-based T-SPOT.TB.

The diagnostic value of IGRAs has focused much less on children than adults [6]. A study conducted in Germany, a country which abandoned BCG vaccination since 1998, found that the sensitivity of QFT-GIT for the diagnosis of childhood TB disease was $93 \%$ [7]. A prospective study of 210 children in Houston, Texas showed that the sensitivity of T-SPOT.TB in culture-confirmed tuberculosis children was $92 \%$ [8]. However, data were sparse in countries with a high coverage of BCG vaccination and a high incidence of TB. In this study, we evaluated the utility of QFT-GIT and T-SPOT.TB among BCG-vaccinated and HIV-negative children for diagnosis of TB for the first time in China. We also investigated the influence of immunosuppressive treatment such as glucocorticoids on the diagnostic performance of IGRA tests.

\section{Methods}

Study setting and population

Children clinically suspected for active tuberculosis with symptoms such as (1) fever, night sweat or weight loss, (2) cough, expectoration, chest pain or hemoptysis, (3) headache, fever or unconsciousness, (4) rash, subcutaneous mass or lymphadenectasis hospitalized at Shanghai Public Health Clinical Center of Fudan University on suspicion of tuberculosis disease were recruited after informed consent was obtained from guardians. All the children were tested with either QFT-GIT or T-SPOT.TB after enrollment. None of the recruited children were co-infected with HIV.

Based on the clinical, radiological, pathological and microbiological findings collected at baseline and during follow-up, the children were grouped into four different diagnostic categories. Definition of case categories is listed in
Table 1 Diagnostic classification of patients

\begin{tabular}{|c|c|}
\hline $\begin{array}{l}\text { Clinical diagnostic } \\
\text { groups }\end{array}$ & Definition of case categories \\
\hline $\begin{array}{l}\text { Confirmed } \\
\text { tuberculosis }\end{array}$ & $\begin{array}{l}\text { Children with clinical specimens positive for } \\
\text { M. tuberculosis in culture or acid-fast bacilli } \\
\text { in microscopy or PCR }\end{array}$ \\
\hline \multirow{11}{*}{$\begin{array}{l}\text { Highly probable } \\
\text { tuberculosis }\end{array}$} & One or more of the following symptoms \\
\hline & $\begin{array}{l}\text { 1. Chest X-ray highly suggestive of active } \\
\text { tuberculosis }\end{array}$ \\
\hline & Miliary findings in HIV-negative children \\
\hline & Nonpyogenic pleural effusion \\
\hline & $\begin{array}{l}\text { Cavitation associated with subacute or chronic } \\
\text { pneumonia }\end{array}$ \\
\hline & Hila or mediastinal lymphadenopathy \\
\hline & $\begin{array}{l}\text { 2. Histology or biopsy tissue showing caseating } \\
\text { granuloma }\end{array}$ \\
\hline & $\begin{array}{l}\text { 3. Abdominal mass or ascites with abdomina } \\
\text { lymphadenopathy on ultrasound scan }\end{array}$ \\
\hline & $\begin{array}{l}\text { 4. Spinal gibbus, destruction or compression } \\
\text { fracture of vertebral bodies or paravertebral } \\
\text { abscess }\end{array}$ \\
\hline & $\begin{array}{l}\text { 5. Symptoms of meningitis with tests of CSF } \\
\text { consistent with tuberculosis meningitis }\end{array}$ \\
\hline & $\begin{array}{l}\text { 6. Clinical improvement with anti-tuberculosis } \\
\text { treatment. }\end{array}$ \\
\hline $\begin{array}{l}\text { Possible } \\
\text { tuberculosis }\end{array}$ & $\begin{array}{l}\text { Children who do not fulfill criteria for } \\
\text { confirmed or highly probable tuberculosis, } \\
\text { but still could not be excluded for active } \\
\text { tuberculosis }\end{array}$ \\
\hline Not tuberculosis & $\begin{array}{l}\text { Excluded from active tuberculosis with an } \\
\text { established alternative diagnosis, and } \\
\text { sustained recovery during } 12 \text { months of } \\
\text { follow-up }\end{array}$ \\
\hline
\end{tabular}

Table 1 [9]. Follow-up visits were scheduled at 1, 2, 5, 6 and 12 months after enrollment. Patients were asked to make unscheduled visits in case their clinical conditions got worse. Results of the QFT-GIT and T-SPOT.TB had no effect on treatment decisions. The study was approved by the institutional review board of Shanghai Public Health Clinical Center.

\section{T-SPOT.TB ${ }^{\circledR}$ and QuantiFERON-TB gold in tube ${ }^{\circledR}$}

The two types of IGRAs tests were performed according to the manufacturers' instructions.

T-SPOT.TB (Oxford Immunotec Ltd., Oxford, UK) is an ELISPOT assay to detect IFN- $\gamma$ induced by ESAT- 6 and CFP-10. The spot forming cells (SFCs) were counted using an automated ELISPOT Reader (AID systems, Strasberg, Germany). Test result of T-SPOT.TB assay would be considered positive if (1) Panel A (containing peptide antigens derived from ESAT-6) and/or Panel B (containing peptide antigens derived from CFP-10) had six or more spots than the negative control when the spots of the 
Fig. 1 Recruitment and diagnostic classification of all participants

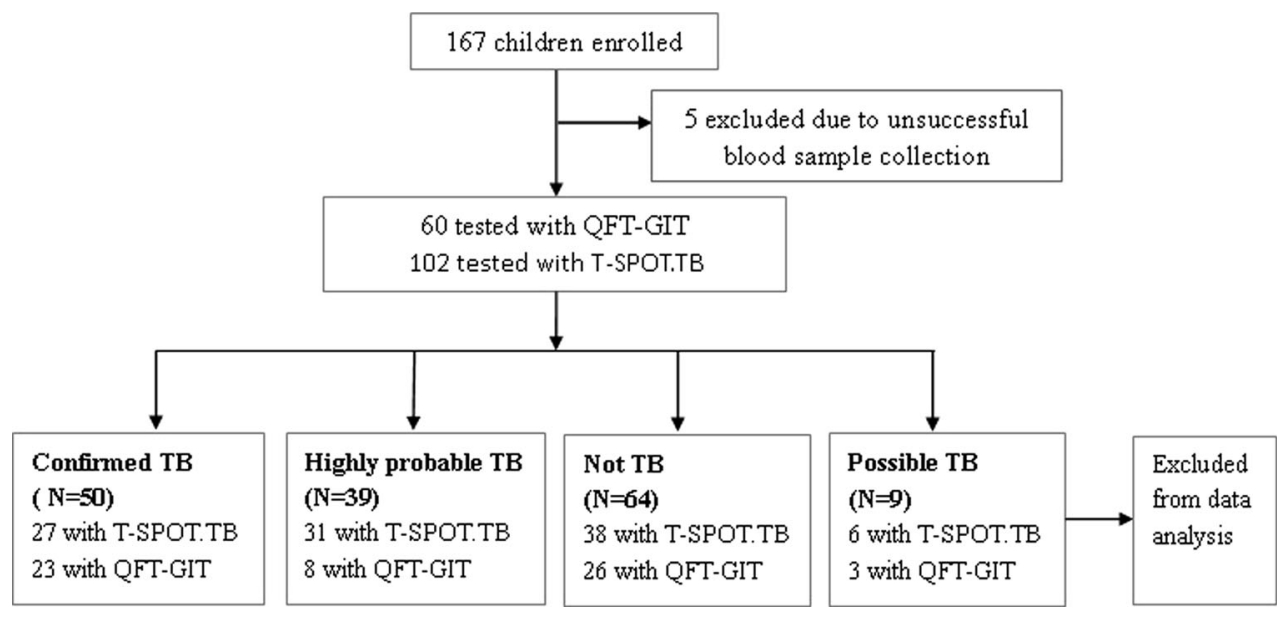

negative control $\leq 5$; (2) the number of spots in Panel A or $B$ was at least two times higher than that of the negative control when there were more than five spots for the negative control. Results were checked by other lab workers and, if necessary, corrected by manual counting.

QuantiFERON-TB Gold in Tube (Cellestis Limited, Carnegie, Victoria, Australia) was performed in two stages. First, $1 \mathrm{~mL}$ of whole blood was collected into each of the specialized blood collection tubes, which included a nil control tube, a TB antigen tube(containing ESAT-6, CFP-10 and TB7.7), and a mitogen tube as a positive control. The tubes were transferred to a $37{ }^{\circ} \mathrm{C}$ incubator. After $16-24$ h of incubation, the tubes were centrifuged and the supernatant was collected. Then the amount of IFN- $\gamma(\mathrm{IU} / \mathrm{mL})$ in the supernatant was measured by ELISA. IFN- $\gamma$ secreted specific to TB antigen was calculated by subtracting the level in nil tube from that in TB antigen tube. Test result would be considered positive if the value is $\geq 0.35 \mathrm{IU} / \mathrm{mL}$ and $\geq 25 \%$ more than the nil control with any value for mitogen tube, and negative if the concentration of the positive control minus negative control is $\geq 0.5 \mathrm{IU} / \mathrm{ml}$, with the calculated value $\geq 0.35 \mathrm{IU} / \mathrm{mL}$ but $<25 \%$ more than the nil control value, or $<0.35 \mathrm{IU} / \mathrm{ml}$. Results were interpreted as indeterminate if (1) the calculated value was $<0.35$, or $\geq 0.35 \mathrm{IU} / \mathrm{mL}$ but $<25 \%$ more than the nil control, both with the positive control minus negative control $<0.5 \mathrm{IU} / \mathrm{mL}$; (2) the value of the nil tube was $>8.0 \mathrm{IU} / \mathrm{mL}$.

\section{Statistical analysis}

Cases with indeterminate result were included into the sum of cases in the calculation of sensitivity and specificity, but not into positive predictive value (PPV) and negative predictive value (NPV). Positive rate in different groups were compared using the $\chi^{2}$ test. $95 \%$ confidence intervals (CIs) were calculated using the Wilson score method. $p<0.05$ were considered to be statistically significant. Data were analyzed by GraphPad Prism 5.

\section{Results}

Study population

Of the 167 children enrolled in this study, five were excluded due to unsuccessful blood collection, 102 were tested with T-SPOT.TB and 60 with QFT-GIT. None of these children had been tested both with QFT-GIT and T-SPOT.TB. Among the 102 children tested with T-SPOT.TB, 27 were diagnosed with confirmed tuberculosis, 31 with highly probable tuberculosis, and 38 without tuberculosis. Among the 60 children with QFT-GIT test, 23 were classified as confirmed tuberculosis, eight with highly probable tuberculosis, and 26 without tuberculosis. Nine cases (six tested with T-SPOT.TB and three tested with QFT-GIT) were unable to get a definite diagnosis and were excluded from data analysis (Fig. 1). For children diagnosed with highly probable TB, hila or mediastinal lymphadenopathy was the most common symptoms. All children with confirmed and highly probable TB received anti-tuberculosis treatment. One child with confirmed TB was lost for follow-up. The remaining 88 children with confirmed TB or highly probable TB showed sustained clinical improvement after initiation of anti-tuberculosis therapy. All the 64 children who were not TB had no active tuberculosis during 12-month follow-up. Clinical samples for microbiological identification included gastric aspirates, induced sputum samples, bronchoscopy lavage fluid, samples from lymph node aspiration, samples from percutaneous biopsy of pulmonary under CT guidance, pericardial stripping organization, pleural fluid samples, ascites, bone marrow and cerebrospinal fluid (CSF). The main characteristics are listed in Table 2.

\section{Results of T-SPOT.TB and QFT-GIT assay}

After excluding those with possible $\mathrm{TB}$, results of the remaining 153 children are listed in Table 3. The 
Table 2 Demographic and clinical details of study subjects

\begin{tabular}{|c|c|c|c|c|c|c|}
\hline \multicolumn{7}{|l|}{ Diagnostic classification } \\
\hline \multirow[t]{2}{*}{ Characteristic } & \multicolumn{2}{|c|}{ Confirmed tuberculosis $(N=50)$} & \multicolumn{2}{|c|}{$\begin{array}{l}\text { Highly probable tuberculosis } \\
(N=39)\end{array}$} & \multicolumn{2}{|c|}{ Not tuberculosis $(N=64)$} \\
\hline & $\begin{array}{l}\text { T-SPOT.TB } \\
(N=27) \text { no. } \%\end{array}$ & $\begin{array}{l}\text { QFT-GIT } \\
(N=23) \text { no. } \%\end{array}$ & $\begin{array}{l}\text { T-SPOT.TB } \\
(N=31) \text { no. } \%\end{array}$ & $\begin{array}{l}\text { QFT-GIT } \\
(N=8) \text { no. } \%\end{array}$ & $\begin{array}{l}\text { T-SPOT.TB } \\
(N=38) \text { no. } \%\end{array}$ & $\begin{array}{l}\text { QFT-GIT } \\
(N=26) \text { no. } \%\end{array}$ \\
\hline Age, median months (IQR) & $45(2-156)$ & $56(3-168)$ & $40(3-160)$ & $42(4-179)$ & $52(2-160)$ & $57.2(3-156)$ \\
\hline Male sex & $15(55.6)$ & $12(52.2)$ & $15(48.4)$ & $4(50.0)$ & $21(55.3)$ & $13(50.0)$ \\
\hline BCG vaccinated & $27(100.0)$ & $23(100.0)$ & $31(100.0)$ & $8(100.0)$ & $38(100.0)$ & $26(100.0)$ \\
\hline Fever & $14(51.9)$ & $14(60.9)$ & $16(51.6)$ & $4(50.0)$ & $14(36.8)$ & $19(73.1)$ \\
\hline Night sweats & $23(85.2)$ & $20(87.0)$ & $11(35.5)$ & $6(75.0)$ & $21(55.3)$ & $15(57.7)$ \\
\hline Cough $>2$ weeks & $19(70.1)$ & $11(47.8)$ & $23(74.2)$ & $5(62.5)$ & $5(13.2)$ & $3(11.5)$ \\
\hline \multicolumn{7}{|l|}{ Chest radiogragh } \\
\hline Normal & $3(8.1)$ & $0(0.0)$ & $4(12.9)$ & $2(25.0)$ & $27(71.1)$ & $8(30.8)$ \\
\hline Abnormal $^{\dagger}$ & $23(85.2)$ & $23(100.0)$ & $27(87.1)$ & $6(75.0)$ & $8(21.1)$ & $16(61.5)$ \\
\hline Not done/unavailable & $0(0.0)$ & $0(0.0)$ & $0(0.0)$ & $0(0.0)$ & $3(7.9)$ & $2(7.7)$ \\
\hline \multicolumn{7}{|l|}{ Tuberculosis type } \\
\hline PTB only & $5(18.5)$ & $5(21.7)$ & $8(25.8)$ & $4(50.0)$ & $0(0.0)$ & $0(0.0)$ \\
\hline EPTB only & $6(22.2)$ & $2(8.7)$ & 4 (12.9) & $3(37.5)$ & $0(0.0)$ & $0(0.0)$ \\
\hline Both PTB and EPTB & $15(55.6)$ & $16(69.6)$ & $19(61.3)$ & $1(12.5)$ & $0(0.0)$ & $0(0.0)$ \\
\hline HIV-infected & $0(0.0)$ & $0(0.0)$ & $0(0.0)$ & $0(0.0)$ & $0(0.0)$ & $0(0.0)$ \\
\hline $\begin{array}{l}\text { Receive prednisolone } \\
\quad(1 \mathrm{mg} / \mathrm{kg} / \text { day }>1 \text { week })\end{array}$ & $1(3.7)$ & $4(17.4)$ & $1(3.2)$ & $1(12.5)$ & $0(0.0)$ & $0(0.0)$ \\
\hline $\begin{array}{l}\text { Receive prednisolone } \\
\quad(1 \mathrm{mg} / \mathrm{kg} / \text { day } \leq 1 \text { week })\end{array}$ & $2(7.4)$ & $7(30.4)$ & $2(6.5)$ & $0(0.0)$ & $0(0.0)$ & $0(0.0)$ \\
\hline $\begin{array}{l}\text { History of tuberculosis close } \\
\text { contact }\end{array}$ & $2(7.4)$ & $5(21.7)$ & $1(3.2)$ & $2(25.0)$ & $0(0.0)$ & $0(0.0)$ \\
\hline
\end{tabular}

$P T B$ pulmonary tuberculosis, EPTB extra-pulmonary tuberculosis

${ }^{\dagger}$ Abnormal chest radiograph included miliary findings, tuberculoma, pleural effusion, cavitation, lymphadenectasis and some other abnormal findings

Table 3 Results of T-SPOT.TB and QFT-GIT in each diagnostic group

\begin{tabular}{|c|c|c|c|c|c|c|}
\hline \multirow[t]{2}{*}{ Result of IGRA } & \multicolumn{2}{|c|}{ Confirmed TB } & \multicolumn{2}{|c|}{ Highly probable TB } & \multicolumn{2}{|l|}{ Not TB } \\
\hline & $\begin{array}{l}\text { T-SPOT.TB } \\
(N=27) \\
\text { no. } \%\end{array}$ & $\begin{array}{l}\text { QFT-GIT } \\
(N=23) \\
\text { no. } \%\end{array}$ & $\begin{array}{l}\text { T-SPOT.TB } \\
(N=31) \\
\text { no. } \%\end{array}$ & $\begin{array}{l}\text { QFT-GIT } \\
(N=8) \\
\text { no. } \%\end{array}$ & $\begin{array}{l}\text { T-SPOT.TB } \\
(N=38) \\
\text { no. } \%\end{array}$ & $\begin{array}{l}\text { QFT-GIT } \\
(N=26) \\
\text { no. } \%\end{array}$ \\
\hline Positive & $20(74.1)$ & $20(87.0)$ & $24(77.4)$ & $6(75.0)$ & $2(5.3)$ & $2(7.7)$ \\
\hline Negative & $7(25.9)$ & $3(13.0)$ & 7 (22.6) & $2(25.0)$ & $36(94.7)$ & $23(88.5)$ \\
\hline Indeterminate & - & $0(0.0)$ & - & $0(0.0)$ & - & $1(3.8)$ \\
\hline
\end{tabular}

positive rate of T-SPOT.TB was $74.1 \%(20 / 27)$ in children with confirmed TB and $77.4 \%$ (24/31) in children with highly probable TB, while the positive rate of QFT-GIT was $87.0 \%(20 / 23)$ in children with confirmed TB and $75.0 \%(6 / 8)$ in children with highly probable TB. Among children with other diseases than TB, 2 were positive for T-SPOT.TB, 2 positive for QFT-GIT, and one child got an indeterminate result of QFT-GIT.
Comparison of the sensitivity and specificity of the T-SPOT.TB and QFT-GIT

The sensitivity of T-SPOT.TB and QFT-GIT for the diagnosis of active TB was $75.9 \%(63.4-85.2 \%)$ and $83.9 \%$ (95\% CI 66.9-93.4\%), respectively. The specificity of T-SPOT.TB and QFT-GIT was $94.7 \%$ (95\% CI $81.8-99.5 \%)$ and $88.5 \% \quad(95 \%$ CI $78.6-99.2 \%)$, respectively. The PPV of T-SPOT.TB and QFT-GIT was 
Table 4 Evaluation index of T-SPOT.TB and QFT-GIT

\begin{tabular}{lllllll}
\hline & Sensitivity $(\%, 95 \%$ CI $)$ & Specificity $(\%, 95 \%$ CI $)$ & PPV (\%, 95 \% CI) & NPV (\%, 95 \% CI) & Positive LR & Negative LR \\
\hline T-SPOT.TB & $75.9(63.4-85.2)$ & $94.7(81.8-99.5)$ & $95.7(84.7-99.6)$ & $72.0(58.2-82.6)$ & 14.3 & 0.25 \\
QFT-GIT & $83.9(66.9-93.4)$ & $88.5(70.2-96.8)$ & $92.9(76.3-99.1)$ & $82.1(63.9-92.6)$ & 7.3 & 0.18 \\
\hline
\end{tabular}

$P P V$ positive predictive value, $N P V$ negative predictive value, $L R$ likelihood ratio

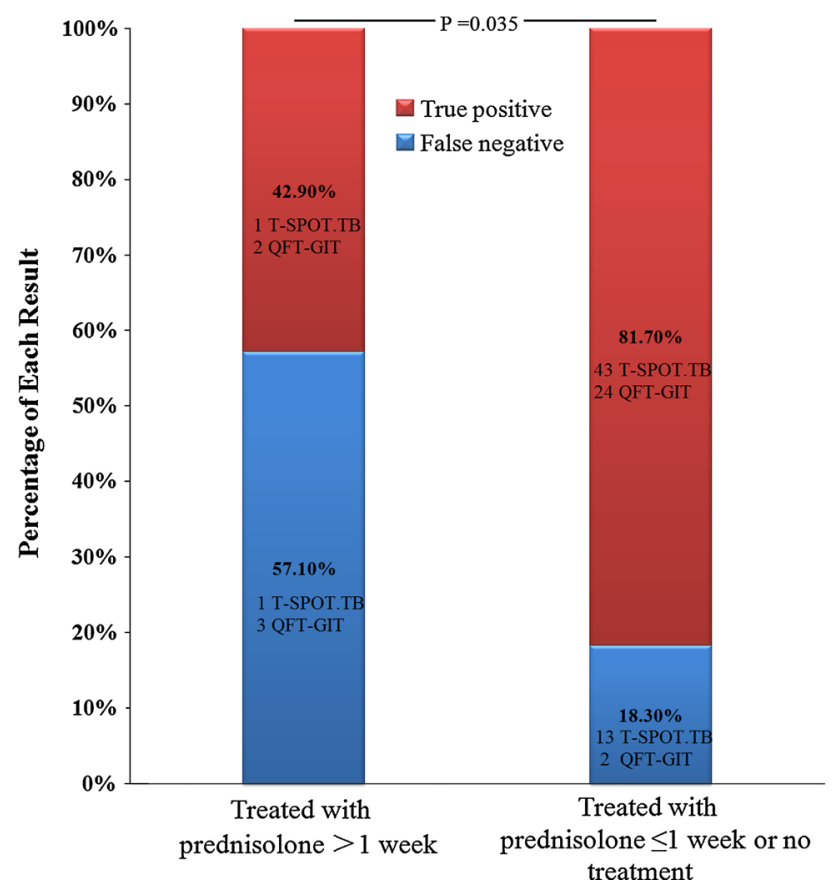

Fig. 2 Effects of prednisolone treatment on T-SPOT.TB and QFTGIT results of children with ATB ( $w$ week)

similar (95.7 vs. $92.9 \%$ ), and NPV of T-SPOT.TB was about $10 \%$ higher than QFT-GIT (82.1 vs. $72.0 \%$ ) (Table 4).

The effect of prednisolone treatment on the risk of false negative results of T-SPOT.TB and QFT-GIT

Six children tested with T-SPOT.TB and 12 children tested with QFT-GIT had received treatment with prednisolone in our study. Prednisolone was prescribed to control the inflammatory reaction in children with tuberculous pleuritis or tuberculous meningitis. In comparison with the numbers of SFCs in panel A and B in T-SPOT.TB or the concentration of IFN- $\gamma$ in TB antigen tube in QFT-GIT, a tendency of decrease in IFN- $\gamma$ release after prednisolone therapy was both observed in T-SPOT.TB (mean SFCs for panel A: 28.8 vs. 58.2, mean SFCs for panel B: 34 vs. 68.9) and QFT-GIT (mean concentration: $3.98 \mathrm{IU} / \mathrm{ml}$ vs. $5.35 \mathrm{IU} / \mathrm{ml}$ ), but the difference was not significant $(p>0.05)$.According to the duration of prednisolone therapy prior to IGRAs, we regrouped the cases into children with prednisolone $(1 \mathrm{mg} /$ $\mathrm{kg} /$ day) for $>1$ week and with prednisolone ( $1 \mathrm{mg} / \mathrm{kg} /$ day $)$ for $\leq 1$ week or without prednisolone treatment. Two children tested with T-SPOT.TB and five children tested with QFT-GIT had been treated with prednisolone for more than 1 week. The false negative rate of T-SPOT.TB and QFT-GIT was $57.1 \%$ (one tested with T-SPOT.TB and three with QFT-GIT) in children with $>1$ week of prednisolone therapy higher than $18.3 \%$ (13 tested with T-SPOT.TB and two with QFT-GIT) of others with shorter/no therapy $(p=0.035)$ (Fig. 2).

The effect of age on the results of T-SPOT.TB and QFT-GIT

We stratified children into two groups according to their age: children $<5$ years old and children $\geq 5$ years old. For children with confirmed and highly probable TB, positive rates of T-SPOT.TB was $66.7 \%$ among children $<5$ years old and $21.3 \%$ higher $(88.0 \%)$ among children $\geq 5$ years old. On the contrary, the positive rate of QFT-GIT was $90 \%$ in children $<5$ years old which was $17.3 \%$ higher than children $\geq 5$ years old. However, the difference was of no significance $(p>0.05)$. For children with not TB, positive rates were a little higher in elder children than in younger children (16.7 vs. $3.1 \%$ for T-SPOT.TB and 10.0 vs. $6.3 \%$ for QFT-GIT), but the differences were also not significant $(p>0.05)$.

\section{Discussion}

Commonly used methods for the diagnosis of childhood tuberculosis have their shortcomings. TST has limited diagnostic value in the areas with a high coverage rate of BCG vaccination because of cross-reactions. Meanwhile, positive rate for sputum culture was low, even for those who got positive result, $50 \%$ were negative for fast sputum-smear test [10]. Therefore, new methods with high accuracy and convenience are urgently needed for better diagnosis of childhood TB. T cell-based IFN- $\gamma$ release assays (IGRAs) are based on the host immune response against $M$. tuberculosis specific antigens, which gives them higher specificity than TST. Previous studies have shown that both QFT-GIT and T-SPOT.TB presented high sensitivity and specificity in adults [5, 11, 12], and showed good value in diagnosing active tuberculosis, 
and identifying latent TB infection [11, 13, 14]. However, there are disagreements on the value of IGRAs in the diagnosis of childhood tuberculosis [7, 15]. Some studies showed that IGRAs had no obvious advantages in children [16-18].

Based on our data, the sensitivity and specificity of QFT-GIT for the diagnosis of childhood TB were both higher than $80 \%$ (83.9 and $88.5 \%)$, while T-SPOT.TB seemed to have a lower sensitivity $(75.9 \%)$ and a higher specificity $(94.7 \%)$ than QFT-GIT without statistical difference. In a meta-analysis done by Sollai S et al.[19], sensitivity of both QFT-GIT and T-SPOT.TB was about $10 \%$ higher among children with microbiologically confirmed TB than that in all TB children. In our study, the rate of bacteriologically confirmed TB was $38.3 \%$ $(23 / 60)$ for QFT-GIT and $26.5 \%$ (27/102) for T-SPOT.TB. The difference of the rate between children receiving two IGRAs may lead to the trend of higher sensitivity of QFT-GIT than T-SPOT.TB. Both types of IGRAs had a high PPV, $95.7 \%$ for T-SPOT.TB and $92.9 \%$ for QFT-GIT. IGRAs presented a better diagnostic value in children in our study than the previous study in adults [20]. Prevalence of latent infection with MTB increases with age, IGRAs performed among children are less affected by latent infection, which increases its value for detecting active tuberculosis in children. For children with suspected TB in a high prevalence area, the high PPV and specificity of the IGRAs would facilitate ruling in childhood TB when a positive result is provided and anti-tuberculosis therapy would accordingly start on those child patients much earlier than microbiological evidence is available. However, we should pay attention that since IGRAs cannot differentiate active TB from latent TB infection, either test should not be used alone to confirm or rule out active TB.

Approximately $20.2 \%(18 / 89)$ of all children with confirmed and highly probable tuberculosis were treated with prednisolone before tested with IGRAs. A statistical difference in the false negative rate was shown between children treated for $>1$ week and those treated with shorter or no prednisolone therapy (57.1 vs. $18.3 \%, p=0.035$ ). Prednisolone can broadly influence biochemical behavior of most cells, and its anti-inflammatory and immunosuppressive action may impair the $\mathrm{T}$ cell proliferation and differentiation in response to TB-specific antigens as shown by the weakened ability of T cells to secrete IFN- $\gamma$ in IGRAs. Previous study showed that immunocompromised children including those receiving glucocorticoid treatment had a higher risk of indeterminate result for QFTGIT test [21], and glucocorticoids taken by oral route impair the response to mitogen more than taken by other ways [22]. In our study, all children took prednisolone intravenously and none of these 12 children got an indeterminate result in QFT-GIT. Young age was considered to influence the performance of IGRAs in children, especially for QFT-GIT. Studies have shown that for children aged $<4$ years old, frequency of indeterminate results was higher [15, 23-26]. However, only one indeterminate result was detected in our study. Studies for the usage of IGRAs in young children $<5$ years of age were limited [27, 28], in our study, positive rates of both IGRAs and QFT-GIT were not significantly different between children $<5$ years old and $\geq 5$ years old.

Our conclusion was limited by the small number of subjects included in the study. A large scale study of effects of glucocorticoids with different duration on performance of IGRAs and the factors associated with indeterminate results in QFT-GIT is needed in the future.

In summary, both IGRA tests showed a good diagnostic value in detecting active childhood tuberculosis in children suspected for active TB in a TB epidemic country. Low incidence of latent TB infection makes IGRAs a better tool in children than in adults. In addition, glucocorticoids can have a negative influence on IGRAs if treated for $>1$ week. In children, age did not affect the performance of IGRAs.

Acknowledgments We would like to thank the staff at the Department of Respiratory of Childrens' Hospital, Fudan University, Shanghai, China, for their work in collecting blood samples. This study was supported by a Youth Grant from Shanghai Municipal Health Bureau (20114Y086). The funders had no role in study design, data collection and analysis, decision to publish or preparation of the manuscript.

Conflict of interest The authors have declared that no competing interests exist.

Informed consent Informed consent was obtained from guardians of each enrolled children, and this study was approved by the institutional review board of Shanghai Public Health Clinical Center.

Open Access This article is distributed under the terms of the Creative Commons Attribution License which permits any use, distribution, and reproduction in any medium, provided the original author(s) and the source are credited.

\section{References}

1. Organization WH. Global tuberculosis control: WHO report 2012. Genava: WHO; 2012.

2. Wang L, Turner MO, Elwood RK, Schulzer M, FitzGerald JM. A meta-analysis of the effect of Bacille Calmette Guerin vaccination on tuberculin skin test measurements. Thorax. 2002;57(9):804-9.

3. Lalvani A. Diagnosing tuberculosis infection in the 21st century: new tools to tackle an old enemy. Chest. 2007;131(6):1898-906. doi:10.1378/chest.06-2471.

4. Diel R, Loddenkemper R, Nienhaus A. Evidence-based comparison of commercial interferon-gamma release assays for detecting active TB: a metaanalysis. Chest. 2010;137(4):952-68. doi:10.1378/chest.09-2350. 
5. Feng Y, Diao N, Shao L, Wu J, Zhang S, Jin J, Wang F, Weng X, Zhang Y, Zhang W. Interferon-gamma release assay performance in pulmonary and extrapulmonary tuberculosis. PLoS ONE. 2012;7(3):e32652. doi:10.1371/journal.pone.0032652.

6. Soysal A, Bakir M. T-SPOT.TB assay usage in adults and children. Expert Rev Mol Diagn. 2011;11(6):643-60. doi:10.1586/ erm.11.46.

7. Detjen AK, Keil T, Roll S, Hauer B, Mauch H, Wahn U, Magdorf $\mathrm{K}$. Interferon-gamma release assays improve the diagnosis of tuberculosis and nontuberculous mycobacterial disease in children in a country with a low incidence of tuberculosis. Clin Infect Dis. 2007;45(3):322-8. doi:10.1086/519266.

8. Cruz AT, Geltemeyer AM, Starke JR, Flores JA, Graviss EA, Smith KC. Comparing the tuberculin skin test and T-SPOT.TB blood test in children. Pediatrics. 2011;127(1):e31-8. doi:10. 1542/peds.2010-1725.

9. Rachow A, Clowes P, Saathoff E, Mtafya B, Michael E, Ntinginya EN, Kowour D, Rojas-Ponce G, Kroidl A, Maboko L, Heinrich N, Reither K, Hoelscher M. Increased and expedited case detection by Xpert MTB/RIF assay in childhood tuberculosis: a prospective cohort study. Clin Infect Dis. 2012;54(10):1388-96. doi:10.1093/cid/cis190.

10. Siddiqi K, Lambert ML, Walley J. Clinical diagnosis of smearnegative pulmonary tuberculosis in low-income countries: the current evidence. Lancet Infect Dis. 2003;3(5):288-96.

11. Kobashi Y, Mouri K, Yagi S, Obase Y, Miyashita N, Okimoto N, Matsushima T, Kageoka T, Oka M. Clinical utility of the QuantiFERON TB-2G test for elderly patients with active tuberculosis. Chest. 2008;133(5):1196-202. doi:10.1378/chest. 07-1995.

12. Sester M, Sotgiu G, Lange C, Giehl C, Girardi E, Migliori GB, Bossink A, Dheda K, Diel R, Dominguez J, Lipman M, Nemeth J, Ravn P, Winkler S, Huitric E, Sandgren A, Manissero D. Interferon-gamma release assays for the diagnosis of active tuberculosis: a systematic review and meta-analysis. Eur Respir J. 2011;37(1):100-11. doi:10.1183/09031936.00114810.

13. Zhang S, Shao L, Mo L, Chen J, Wang F, Meng C, Zhong M, Qiu $\mathrm{L}$, Wu M, Weng X, Zhang W. Evaluation of gamma interferon release assays using Mycobacterium tuberculosis antigens for diagnosis of latent and active tuberculosis in Mycobacterium bovis BCG-vaccinated populations. Clin Vaccine Immunol. 2010;17(12):1985-90. doi:10.1128/CVI.00294-10.

14. Diel R, Loddenkemper R, Meywald-Walter K, Gottschalk R, Nienhaus A. Comparative performance of tuberculin skin test, QuantiFERON-TB-Gold In Tube assay, and T-Spot.TB test in contact investigations for tuberculosis. Chest. 2009;135(4):1010-8. doi:10.1378/chest.08-2048.

15. Rose MV, Kimaro G, Nissen TN, Kroidl I, Hoelscher M, Bygbjerg IC, Mfinanga SG, Ravn P. QuantiFERON(R)-TB gold intube performance for diagnosing active tuberculosis in children and adults in a high burden setting. PLoS ONE. 2012;7(7):e37851. doi:10.1371/journal.pone.0037851.

16. Dogra S, Narang P, Mendiratta DK, Chaturvedi P, Reingold AL, Colford JM Jr, Riley LW, Pai M. Comparison of a whole blood interferon-gamma assay with tuberculin skin testing for the detection of tuberculosis infection in hospitalized children in rural India. J Infect. 2007;54(3):267-76. doi:10.1016/j.jinf.2006. 04.007.

17. Tavast E, Salo E, Seppala I, Tuuminen T. IGRA tests perform similarly to TST but cause no adverse reactions: pediatric experience in Finland. BMC Res Notes. 2009;2:9. doi:10.1186/ 1756-0500-2-9.

18. Nicol MP, Davies MA, Wood K, Hatherill M, Workman L, Hawkridge A, Eley B, Wilkinson KA, Wilkinson RJ, Hanekom WA, Beatty D, Hussey G. Comparison of T-SPOT.TB assay and tuberculin skin test for the evaluation of young children at high risk for tuberculosis in a community setting. Pediatrics. 2009;123(1):38-43. doi:10.1542/peds.2008-0611.

19. Sollai S, Galli L, de Martino M, Chiappini E. Systematic review and meta-analysis on the utility of Interferon-gamma release assays for the diagnosis of Mycobacterium tuberculosis infection in children: a 2013 update. BMC Infect Dis. 2014;14(Suppl 1):S6. doi:10.1186/1471-2334-14-S1-S6.

20. Metcalfe JZ, Everett CK, Steingart KR, Cattamanchi A, Huang L, Hopewell PC, Pai M. Interferon-gamma release assays for active pulmonary tuberculosis diagnosis in adults in low- and middleincome countries: systematic review and meta-analysis. J Infect Dis. 2011;204(Suppl 4):S1120-9. doi:10.1093/infdis/jir410.

21. Haustein T, Ridout DA, Hartley JC, Thaker U, Shingadia D, Klein NJ, Novelli V, Dixon GL. The likelihood of an indeterminate test result from a whole-blood interferon-gamma release assay for the diagnosis of Mycobacterium tuberculosis infection in children correlates with age and immune status. Pediatr Infect Dis J. 2009;28(8):669-73. doi:10.1097/INF.0b013e3181a16394.

22. Belard E, Semb S, Ruhwald M, Werlinrud AM, Soborg B, Jensen FK, Thomsen H, Brylov A, Hetland ML, Nordgaard-Lassen I, Ravn P. Prednisolone treatment affects the performance of the QuantiFERON gold in-tube test and the tuberculin skin test in patients with autoimmune disorders screened for latent tuberculosis infection. Inflamm Bowel Dis. 2011;17(11):2340-9. doi:10. 1002/ibd.21605.

23. Bergamini BM, Losi M, Vaienti F, D’Amico R, Meccugni B, Meacci M, De Giovanni D, Rumpianesi F, Fabbri LM, Balli F, Richeldi L. Performance of commercial blood tests for the diagnosis of latent tuberculosis infection in children and adolescents. Pediatrics. 2009;123(3):e419-24. doi:10.1542/peds.20081722.

24. Banfield S, Pascoe E, Thambiran A, Siafarikas A, Burgner D. Factors associated with the performance of a blood-based interferon-gamma release assay in diagnosing tuberculosis. PLoS ONE. 2012;7(6):e38556. doi:10.1371/journal.pone.0038556.

25. Critselis E, Amanatidou V, Syridou G, Spyridis NP, Mavrikou M, Papadopoulos NG, Tsolia MN. The effect of age on whole blood interferon-gamma release assay response among children investigated for latent tuberculosis infection. $\mathrm{J}$ Pediatr. 2012;161(4):632-8. doi:10.1016/j.jpeds.2012.04.007.

26. Thomas TA, Mondal D, Noor Z, Liu L, Alam M, Haque R, Banu S, Sun H, Peterson KM. Malnutrition and helminth infection affect performance of an interferon gamma-release assay. Pediatrics. 2010;126(6):e1522-9. doi:10.1542/peds.2010-0885.

27. Debord C, De Lauzanne A, Gourgouillon N, Guerin-El Khourouj V, Pedron B, Gaudelus J, Faye A, Sterkers G. Interferon-gamma release assay performance for diagnosing tuberculosis disease in 0- to 5-year-old children. Pediatr Infect Dis J. 2011;30(11):995-7. doi:10.1097/INF.0b013e3182272227.

28. Pavic I, Topic RZ, Raos M, Aberle N, Dodig S. Interferongamma release assay for the diagnosis of latent tuberculosis in children younger than 5 years of age. Pediatr Infect Dis J. 2011;30(10):866-70. doi:10.1097/INF.0b013e318220c52a. 